\title{
Methodological Approach to Assessing the Effectiveness of Managing the Investment Potential of International Financial Corporations
}

\section{Sergey Chernogorskiy}

Peter the Great Saint Petersburg Polytechnic University: Sankt-Peterburgskij politehniceskij universitet

Petra Velikogo

Konstantin Kostin ( $\square$ kost_kos@mail.ru )

Saint-Petersburg State University of Economics

\section{Bernd Mühlfriedel}

University of Applied Sciences in Landshut

\section{Research Article}

Keywords: management, investment potential, management technology, model, graph, synthesis, adequacy, inverse management problem

Posted Date: March 10th, 2021

DOl: https://doi.org/10.21203/rs.3.rs-250941/v1

License: (c) (i) This work is licensed under a Creative Commons Attribution 4.0 International License. Read Full License 


\title{
Methodological approach to assessing the effectiveness of managing the investment potential of international financial corporations
}

\author{
Sergey Chernogorskiy ${ }^{1}$, Konstantin Kostin ${ }^{2, *}$ and Bernd Mühlfriedel ${ }^{3}$ \\ 1 Graduate School of Industrial economics, National Technology Initiative Center for Advanced \\ Manufacturing Technologies based on the Institute of Advanced Manufacturing Technologies of Peter the \\ Great St. Petersburg Polytechnic University, 195251 St. Petersburg, Russia; chernog_sa@spbstu.ru \\ 2 Saint-Petersburg State University of Economics, 191023 St. Petersburg, Russia; kost kos@mail.ru \\ 3 University of Applied Sciences in Landshut, Am Lurzenhof 1, 84036 Landshut, Germany; \\ bernd.muehlfriedel@haw-landshut.de \\ * Correspondence: kost_kos@mail.ru;
}

\begin{abstract}
Assessing the management of the investment potential of international financial corporations is an important research problem, since it helps to substantiate the significance of decisions made, which increases the efficiency of international corporations in general. One of the main indicators that evaluate the quality of enterprise management is operational efficiency. The effectiveness of the enterprise means the ability of the enterprise to ensure the constant production of material (information, social, etc., depending on the segment of the enterprise) goods, in any given situation. This article touches upon the issue of assessing the effectiveness of managing the investment potential of an enterprise. The general approach to the methodology is based on a model of making a personal decision based on synthesis, while a personal decision is being the basis of any activity, regardless of the sphere of management. The article uses a methodology for assessing the effectiveness, based on the construction of a complex system. The methodology is also stipulated by: firstly, the basic laws of the subject area (basic physical, social and technical laws), and secondly, the ultimate goal of the system development. This approach is based on the system integration of the basic processes for managing the investment potential of the enterprise and represents a solution to the inverse management problem. This synthesis-based approach ensures the achievement of the goal of management. Within the process of development of the approach to assessing the effectiveness of managing the investment potential of an enterprise, a synthesis-based mathematical model was developed.
\end{abstract}

Keywords: management, investment potential, management technology, model, graph, synthesis, adequacy, inverse management problem

\section{Introduction}

At present, the question of managing the investment potential of an enterprise is one of the most important issues in production, since the effectiveness of an enterprise depends on the level of staff qualification and on the relevant investment decisions [1-10].

The task that faces the technology for investment potential management is to eliminate the existing contradictions and to create a model of the investment potential management process based on a unified approach [11-18].

The proposed model guarantees the achievement of a given rate of return and it is suitable for scaling to various areas of investment activity being adequate to the external environment. Within the development process, a natural-scientific method was used. It means integration of the human mental process together with the cognition and environment. The main challenges resolved within the research were the following three aspects: 
- methodological - obtaining the conditions that enable the investment potential management processes,

- methodical - development of a method that will provide the conditions for the transfer of the management object from the present state to the required one;

- technological - determining the conditions for the process of transferring the managerial object from the present state to the required one $[19,20]$

In order to eliminate all possible contradictory conclusions, the formal-axiomatic approach was used [21]. It assumes some basic assumptions reflected in basic principles, the basic concepts are axioms, the inference rules and theorems [22]. The research based on the formal axiomatic method is usually called deductive [23]. All the concepts of deductive theory (except for a fixed number of initial ones) are introduced through evidence expressing (or clarifying) them through the previously introduced concepts [24].

\section{Formulation of the problem}

The task of developing a methodology for evaluating the effectiveness of managing the investment potential of an enterprise boils down to an analysis of the decision options of the entity making the corresponding investment decisions (hereinafter - EMD), since - it is the decision that makes up the basis of human activity [25].

Management of the investment process requires that the processes are formed with the predetermined properties. The paper presents a synthesis-based management concept that can satisfy these requirements [26]. Investment management is usually built on a large statistical dataset. Obtaining and processing data for investment decision-making is the most important and timeconsuming stage of creating such information systems [27]. This statistical data can be used for decision-making by an authorized decision maker (EMD). Here emerges the problem of establishing a link between the dataset and the decision-making model so that the desired return on investment can be guaranteed. However, without the methodological foundations for solving the problem of managing the investment potential, i.e. a condition for the existence of the process, one cannot guarantee the achievement of the goal. The basis of human activity is the decision itself [28]. A person carries out his activities on the basis of a model. Hence, for conducting activities corresponding to the investment environment, one should have an adequate mathematical model for decision making. In publications on this topic the problem of building a mathematical model for decision making is considered as complex or sometimes even as an impossible task. One should note that the publications present only the results of the decision rationale, but not the model itself. Without a mathematical decision-making model, it is difficult to guarantee the achievement of the goal of investment potential management. The same situation occurs with the construction of the investment potential management system, since there is no criterion for the synthesis of a properly constructed system [29]. This set of factors determines the relevance of this research. The goal of the research is the choice and justification of the conditions that make the achievement of the goal of managing the investment potential with the help of a mathematical decision-making model. Only a condition for the existence of the process of managing the investment potential will make the connection of statistical data with the elements of a mathematical model for decision-making possible. Obtaining the conditions for existence of the process of managing the investment potential allows for the creation of a constructive technology. Investment potential management technology is in essence a transformation of the information and activity resources of the EMD in the interests of achieving the goal [30].

\section{A general approach to the synthesis of an investment decision model in managing the investment potential}

For the purpose of construction of the investment decision model the natural-scientific approach (NSA) is used. It is based on the object integrity conservation law (OICL). The law of conservation of the integrity of the object is a stable, repeating relationship between the properties of the object and 
the properties of the action for a fixed purpose. OICL is manifested in the mutual transformation of the properties of the object and the properties of its action for a fixed purpose.

In accordance with the developed NSA, each investment process should be represented by three components that correspond to the properties of "objectivity", "integrity" and "variability" (or the notions of "object - investment", "purpose" and "action", respectively). The components of the investment decision are located horizontally. They can be interpreted at three different levels of investment perception (the abstract level, the abstract-specific and specific levels). This approach determines three vertical levels: methodological, methodical and technological. In Fig. 1 a structural diagram of the "Investment decision" concept is presented [31].

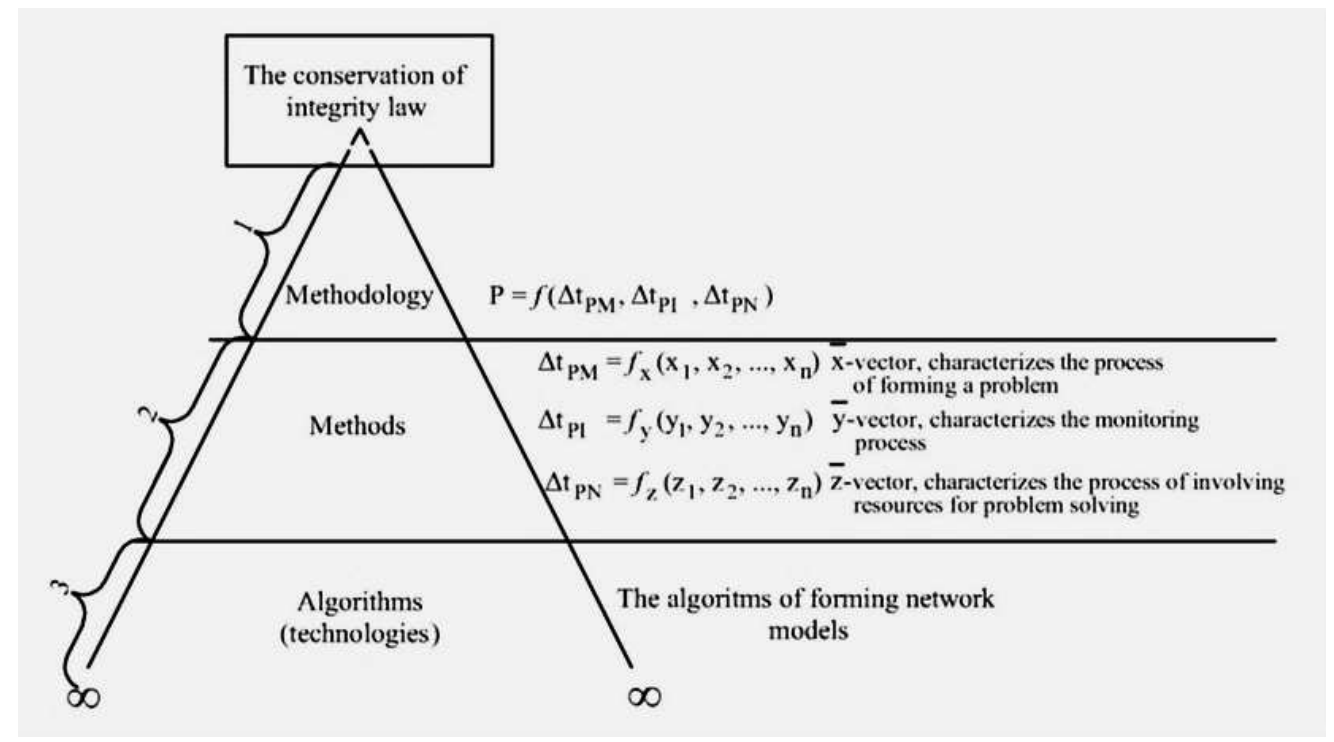

Figure 1. The structural diagram of the "Investment decision" concept [31,32].

A number of definitions are to be introduced.

A managerial investment decision is a condition needed for realizing the object's purpose - i.e. investments that the EMD manages in the appropriate investment environment in order to achieve the management goal.

The investment environment is a set of factors and conditions in which investment activity is carried out. Informational and analytical work is the continuous collection, study, display and analysis of the data on the investment environment.

Having decomposed the concept of "managerial investment decision" into three basic elements - "investment environment", "informational-and-analytical work" and "investment decision", we move on to the next stage - the synthesis of an investment decision model. In Fig. 2 a structural diagram of the model synthesis is presented [31,33-36].

It is known from systems engineering that there are only two approaches to model construction: the analysis- and the synthesis-based ones. The analysis-based approach has a significant drawback: the formation of the processes with predetermined properties is not allowed. However, in terms of managing the investment potential it has special significance. The synthesis-based approach guarantees achievement of the goal and is devoid of the main drawback of the previous approach. So, the synthesis-based approach was used in the research.

At the methodological level while using the decomposition method, we divide the decision into three elements ("investment environment", "investment decision" and "info-analytical work"), which correspond to "object - investment", "purpose" and "action". Applying the method of abstraction at the methodological level, we identify "object - investment" ("investment environment") with the frequency the problem emerges $\left(\Delta t_{P M}\right)$. 


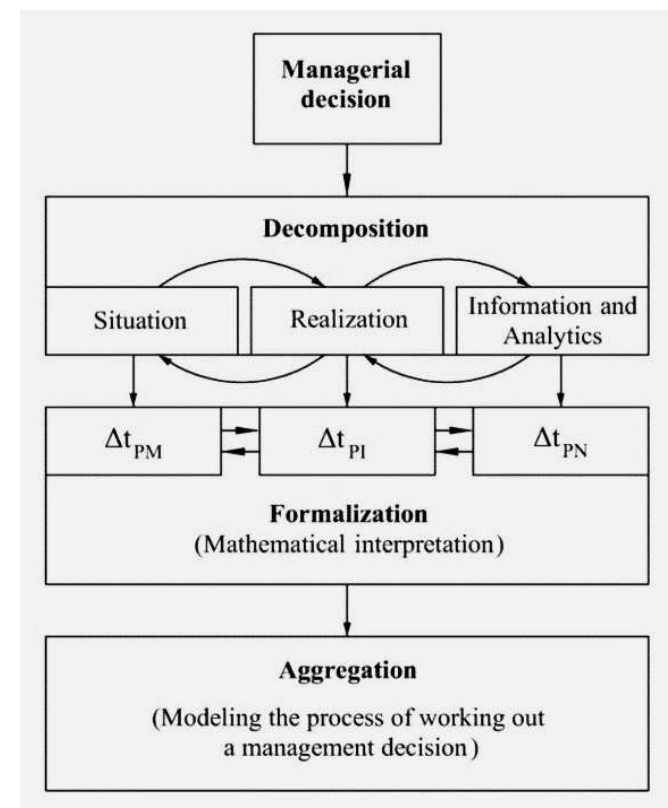

Figure 2. Structural diagram of the synthesis process of the model construction [37,32].

The "purpose" ("investment decision") is identified with the frequency the problem is being neutralized (average time for an adequate response to the problem) by a person $\left(\Delta t_{P N}\right)$. The "action" ("info-analytical work") is identified with the frequency the problem emerges (the average time to recognize the investment environment) $\left(\Delta t P_{I}\right)$. The temporal characteristics are justified by the fact that only resources of time are irretrievable. It should be noted that the results of the research in the theory of functional systems of the academician of the USSR Academy of Sciences P.K. Anokhin showed that a person's decision is formed in the pattern of "excitement", "recognition", "reaction to the environment". Therefore, in this work, we use the diagram of changes in the basic components of the construction of the investment decision model, presented in Fig. 3 [37].

a)
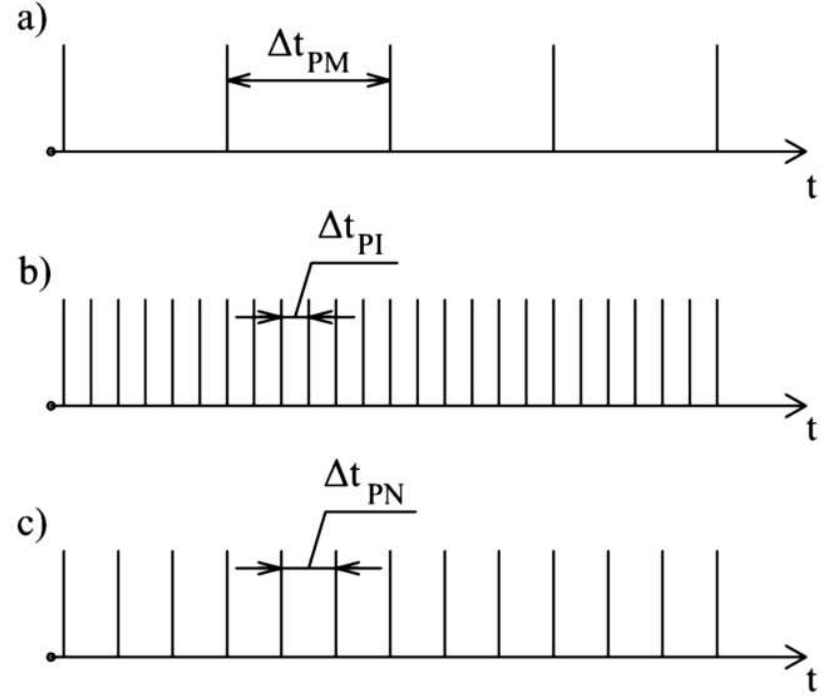

Figure 3. A diagram of the basic elements in the construction of the investment decision model $[31,37]$.

\section{The synthesis of the investment potential management model}

As a result of applying the methods of decomposition, abstraction and aggregation, the concept of "managerial investment decision" was transformed into an aggregate - a mathematical model of managerial investment decision of the following form: 


$$
P=F\left(\Delta t_{P M}, \Delta t_{P I}, \Delta t_{P N}\right),
$$

where $\Delta t_{P M}$ - generalized characteristics of the investment environment, $\Delta t_{P I}$ - info-analytical work and $\Delta t_{P N}$ - neutralization of the investment problem.

This is the condition for existence of a process for managing the investment potential. Due to the fact that the basic model of managerial investment decision has three elements, the control block diagram will be presented in the form shown in Fig. 4.

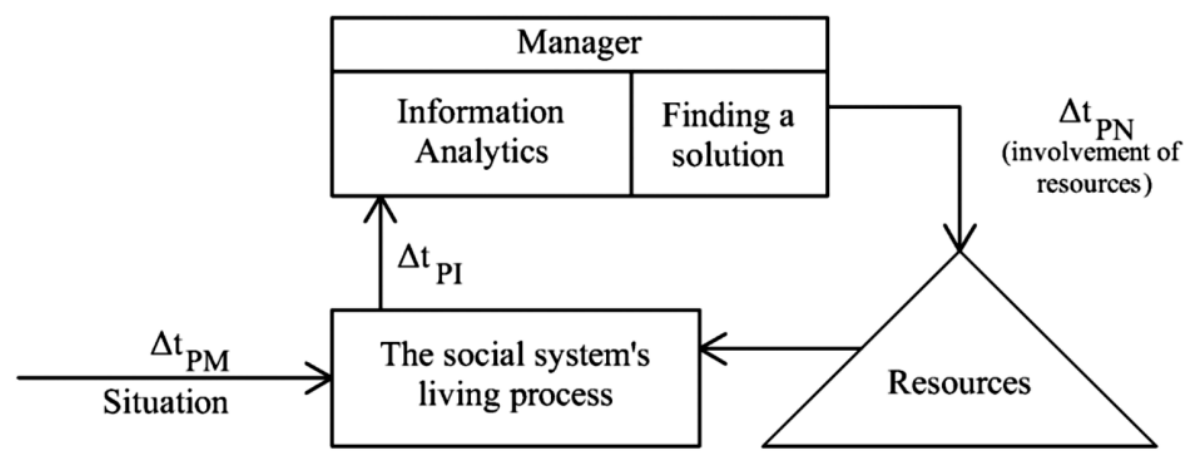

Figure 4. The block diagram of the investment process management [38],

$\lambda$ is the reciprocal value of the average time the investment problem emerges; $v_{1}$ is the reciprocal value of the average time of identification of the investment problem;

$v_{2}$ is the reciprocal value of the average time the investment problem is neutralized.

The EMD while managing the investment potential can perform two functions in various combinations:

- to identify (recognize) an investment problem,

- to neutralize (to use resources of investment potential management system) the investment problem.

In accordance with the above, the decision-making model characterizes four basic conditions for the EMD:

Aoo - the EMD is not identifying or neutralizing an investment problem,

$A_{10}$ - the EMD identifies but does not neutralize the investment problem,

A01 - the EMD does not identify and neutralize the investment problem,

$A_{11}$ - the EMD identifies and neutralizes the investment problem.

In accordance with the described feature of the managerial investment decision, it is necessary to introduce the probabilities of finding our investment potential management system in these four states. Accordingly, we obtain the probabilities $P_{00}, P_{10}, P_{01}, P_{11}$ corresponding to the states of the investment potential management system - $A_{00}, A_{10}, A_{01}, A_{11}$. The process of obtaining the investment decision can be considered as a Markov chain. Due to the fact that this approach does not allow taking into account the dynamics of the investment process, continuous Markov chains are used further in this paper. To implement this approach, it is necessary to compose a system of KolmogorovChapman differential equations.

The basic model of managerial investment decision has three elements, therefore the structural management scheme can be presented as follows: in Fig. 5 the $\lambda$ - value is the inverse value of the average time interval the investment problem emerges; $v_{1}$ - is the reciprocal value of the average time of identification of the investment problem; $v_{2}$ - is the reciprocal value of the average time needed to neutralize the investment problem.

We assume that initially the system is in the state Aoo. When a problem occurs under the influence of intensity $\lambda$, the system shifts to the state $A_{10}$, i.e., into the state of recognition of the investment problem. From this state, the system under the influence of intensity $v_{1}$ shifts to state $A_{01}$, the system starts the process of neutralizing the investment problem with intensity $v_{2}$ and the system then occurs in state Aoo. This situation is possible if the investment problem is neutralized, and the 
next investment problem has not yet emerged. If some problem emerges, under the influence of intensity $\lambda$, the system goes into state $A_{11}$. While being in state $A_{11}$, under the influence of intensity $v_{1}$, the system goes into state $A_{01}$ if the problem is recognized, and goes into state $A_{10}$ under the influence of intensity $v_{1}$ if the problem is neutralized. Afterwards, a further problem emerges and needs to be recognized. The process is repeated.

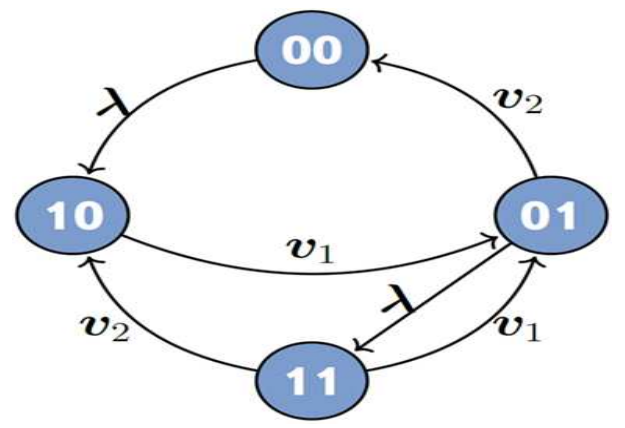

Figure 5. The graph of states of the system [designed by authors]

For describing the process of changing states on the graph, the following assumptions should be made:

1. The research touches upon the formation of an investment decision with the help of an information management system. The process for managing the investment potential is formed on the basis of the decision.

2. The time intervals between the moments when investment problems pop up are random variables.

3. The discovered problems form in time a stream close to the Poisson stream.

4. The processing time of the data on the required attribute is a random variable.

5. After data processing, the distribution between the involved efforts and funds (resources) takes place. It all serves for solving the problem of managing investment potential.

6. The research considers the case when the time intervals in which the investment problems occur are very limited both in the field of the system or human capacity and this time intervals can be very close to the time necessary for the problem identification, as well as processing the investment data and taking adequate actions.

7. The system is prepared for the tasks of recognizing and neutralizing of the investment problems.

8. The system being developed (human decision support system) is designed to assess the potential capabilities of the investment potential management system depending on the environment. Taking these assumptions into account, the Kolmogorov system of differential equations was used:

$$
\frac{d P_{i}(t)}{d t}=\sum_{j=1}^{n} \lambda_{j i}(t) \cdot P_{j}(t)-P_{i}(t) \cdot \sum_{j=1}^{n} \lambda_{i j}(t)
$$

where $i=1,2, \ldots, n$.

In order to compose the Kolmogorov differential equation for the function $P_{i}(t), i=1,2, \ldots, n$, one has to write the derivative $\frac{d P_{i}(t)}{d t}$ of the function $P_{i}(t)$ on the left side of this equation. On the right side of the equation, the product $\sum_{j=1}^{n} \lambda_{i j}(t) P_{i}(t)$ of the sum $\sum_{j=1}^{n} \lambda_{i j}(t)$ of the probability densities of transitions $\lambda_{i j}$ of the arrows going out of the state $S_{i}$ by the probability $P_{i}(t)$ of this state with a minus sign, plus the sum $\sum_{j=1}^{n} \lambda_{i j}(t) P_{i}(t)$ of the products $\lambda_{i j} P_{i}(t)$ of transition probability densities $\lambda_{i j}$ corresponding to the arrows entering the state $S_{i}$ multiplied by the probabilities of the states from which these arrows go out. Here the transition probability densities $\lambda_{i j}$ corresponding to the missing arrows on the graph are equal to zero (see Fig. 5).

The resulting probabilities of the states can be obtained by solving a system of linear algebraic equations that are obtained from Kolmogorov differential equations if the derivatives are equated to zero, and the probability functions of the states $P_{i}(t), \ldots, P_{n}(t)$ on the right-hand sides of the equations 
are replaced, respectively, by unknown resulting probabilities. To find the exact value of $P_{i,} \ldots, P_{n}$, a condition of $P_{0}+P_{1}+\ldots+P_{n}=1$ is added to the system of equations.

While performing its' tasks, the EMD may be in two situations:

1. The current situation in the management of investment potential does not allow the EMD to resolve the problem, due to lack of qualification.

2. The qualification of the EMD allows solving the investment problem, but only when some additional time resources are used. In order to implement these two basic situations in the model, four basic states have to be distinguished:

- State 1 characterizes the investment potential at the beginning of the management process under consideration.

- State 2 is a state that characterizes the achievement of the managerial goal that is the desired investment potential. In this state, there are two ways for the situation to develop. The first one occurs when an unacceptably large amount of time was spent on achieving the final goal, which means a failure to solve the managerial problem, so the system shifts to state 1 . The second one is spending some acceptable amount of time on achieving the goal, so, the managerial goal has been achieved.

- State 3 is a state that is characterized by an emergence of the investment problem, given that in the managerial process there are both regular situations with well-known response mechanisms, and emergency situations where the investment problem cannot be solved unless the EMD finds some additional resources. In this state, it becomes necessary to identify the investment problem and determine the necessary resources.

- State 4 is a state that characterizes a situation when the EMD understands clearly how to solve an investment problem. In this state all the necessary resources are at hand and once again two scenarios are possible. The first scenario is the situation where the EMD is not ready to solve the investment problem, therefore, the return to state 1 goes thereafter and the management problem has not been solved. The second scenario means that the EMD is able to solve the investment problem, but only with additional time costs. In this case, the system goes to state 2 .

If the EMD is unable to identify the situation and take adequate measures, the transition from state 4 to state 1 occurs. Here the frequency of transition $v_{3}$ is an indicator of the qualification level of the EMD.

The average time needed to complete the managerial goal is characterized by the frequency $\zeta^{+}=1 / T_{\ni}$ (the reciprocal of the average time needed to achieve the goal) of the system shifting from state 1 to state 2 . The average frequency of failure of the investment potential management process is characterized by the frequency $\zeta^{-}$.

According to this logic, the process of investment potential management can be presented as a graph of states of the system (see Fig. 6)

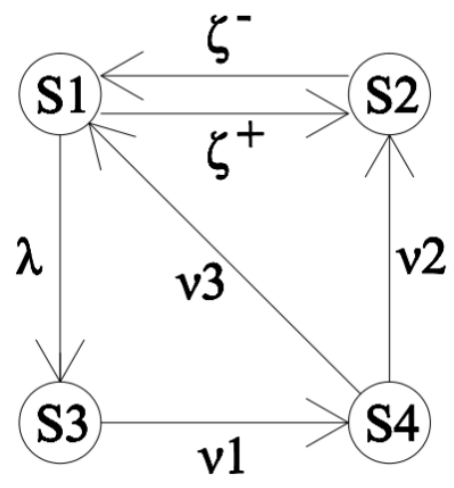

Figure 6. Graph of states of the system [designed by authors]

For the graph shown in Figure 6, the Kolmogorov system of equations will take the form: 


$$
\left\{\begin{array}{l}
\frac{d P_{1}(t)}{d t}=-\left(\zeta^{+}+\lambda\right) \cdot P_{1}(t)+\zeta^{-} \cdot P_{2}(t)+v_{3} \cdot P_{4}(t) \\
\frac{d P_{2}(t)}{d t}=\zeta^{+} \cdot P_{1}(t)-\zeta^{-} \cdot P_{2}(t)+v_{2} \cdot P_{4}(t) \\
\frac{d P_{3}(t)}{d t}=\lambda \cdot P_{1}(t)-v_{1} \cdot P_{3}(t) \\
\frac{d P_{4}(t)}{d t}=v_{1} \cdot P_{3}(t)-\left(v_{3}+v_{2}\right) \cdot P_{4}(t) .
\end{array}\right.
$$

Thus, the final probabilities can be obtained by solving a system of linear equations:

$$
\left\{\begin{array}{l}
0=-\left(\zeta^{+}+\lambda\right) \cdot P_{1}+\zeta^{-} \cdot P_{2}+v_{3} \cdot P_{4}, \\
0=\zeta^{+} \cdot P_{1}-\zeta^{-} \cdot P_{2}+v_{2} \cdot P_{4}, \\
0=\lambda \cdot P_{1}-v_{1} \cdot P_{3} \\
1=P_{1}+P_{2}+P_{3}+P_{4} .
\end{array}\right.
$$

The solution of the system takes the view:

$$
\begin{aligned}
& P_{1}=\frac{v_{1} v_{2} \zeta^{-}+v_{1} v_{3} \zeta^{-}}{\lambda v_{1} v_{2}+\lambda v_{1} \zeta^{-}+\lambda v_{3} \zeta^{-}+v_{1} v_{2} \zeta^{+}+v_{1} v_{2} \zeta^{-}+v_{1} \zeta^{+} v_{3}+v_{1} v_{2} \zeta^{-}} \\
& P_{2}=\frac{\lambda v_{1} v_{2}+v_{1} v_{2} \zeta^{+}+v_{1} \zeta^{+} v_{3}}{\lambda v_{1} v_{2}+\lambda v_{1} \zeta^{-}+\lambda v_{3} \zeta^{-}+v_{1} v_{2} \zeta^{+}+v_{1} v_{2} \zeta^{-}+v_{1} \zeta^{+} v_{3}+v_{1} v_{2} \zeta^{-}} \\
& P_{3}=\frac{\lambda v_{1} \zeta^{-}+\lambda v_{3} \zeta^{-}}{\lambda v_{1} v_{2}+\lambda v_{1} \zeta^{-}+\lambda v_{3} \zeta^{-}+v_{1} v_{2} \zeta^{+}+v_{1} v_{2} \zeta^{-}+v_{1} \zeta^{+} v_{3}+v_{1} v_{2} \zeta^{-}} \\
& P_{4}=\frac{\lambda v_{1} \zeta^{-}}{\lambda v_{1} v_{2}+\lambda v_{1} \zeta^{-}+\lambda v_{3} \zeta^{-}+v_{1} v_{2} \zeta^{+}+v_{1} v_{2} \zeta^{-}+v_{1} \zeta^{+} v_{3}+v_{1} v_{2} \zeta^{-}}
\end{aligned}
$$

Having obtained the ratios that determine the probabilities of possible states $A_{00}, A_{10}, A_{01}, A_{11}$ of the system, we can develop the requirements for the properties of the process of recognizing the investment problem. Furthermore, the properties for the process of problem neutralizing can be determined within the investment potential management system. The probability that the investment problem will be identified and neutralized by the investment potential management system is determined by the ratio:

$$
P_{2}=\frac{\lambda v_{1} v_{2}+v_{1} v_{2} \zeta^{+}+v_{1} \zeta^{+} v_{3}}{\lambda v_{1} v_{2}+\lambda v_{1} \zeta^{-}+\lambda v_{3} \zeta^{-}+v_{1} v_{2} \zeta^{+}+v_{1} v_{2} \zeta^{-}+v_{1} \zeta^{+} v_{3}+v_{1} v_{2} \zeta^{-}}
$$

This expression is an indicator of the effectiveness of investment potential management in the enterprise.

This ratio combines six parameters together. Thus, the analytical dependence of the generalized characteristics of the investment environment $\left(\Delta t_{P M}\right)$, info-analytical activity $\left(\Delta t_{P I}\right)$ and the neutralization of the investment problem $\left(\Delta t_{P N}\right)$ has been determined.

\section{The results of the study}

The following dependence will serve as an indicator of the effectiveness of the investment potential management model, depending on the different socio-economic conditions:

$$
P_{2}=f\left(\lambda, v_{1}, v_{2}, v_{3}, \zeta^{+}, \zeta^{-}\right)
$$

where $\lambda$ is the value $\lambda=1 / \Delta t_{P M}$, where $\Delta t_{P M}$ - is the average time period the investment problem occurs;

$v_{1}$ is the value $v_{1}=1 / \Delta t_{P I}$, where $\Delta t_{P I}$ is the average time needed to identify the investment problem;

$v_{2}$ is the value $v_{2}=1 / \Delta t_{P N}$, where $\Delta t_{P N}$ is the average time needed to neutralize the investment problem;

$v_{3}$ is the frequency of failure of the EMD to neutralize the problem, due to the inability to recognize the investment environment (the indicator of EMD qualification);

$\zeta^{+}$is the value $\left(\zeta^{+}=1 / T_{\ni}\right)$, where $T_{\ni}$ is the duration of solving the investment problem;

$\zeta^{-}$is the frequency of the investment plan failure (failure to fulfill the investment task); 
$P_{2}$ is an indicator of the effectiveness of the managerial decisions in investment potential management process.

\section{Conclusion}

The synthesis-based modeling approach enables creation of a system for managing the investment potential with the required level of effectiveness. Accordingly, the system based on such principles will be deprived of the main drawback - the inconsistency of the managerial results and the expectations of the EMD [39-42]. Such an approach allows to evaluate any decision from the standpoint of time and resources spent, as well as to establish a clear, scientifically sound relationship between the decision and the results of the action. The development of the methodology makes it possible to proceed to the development of methods for the practical application of results in international business. In this regard further work in this field will focus on the practical side of the issues of effectiveness of investment potential management.

Considering relation (1) as a condition for the existence of the investment potential management process, setting an indicator of the level of investment potential in the form (1) and having at the same time the characteristic of the investment environment $\Delta t_{P M}=f_{1}\left(x_{1}, x_{22} \ldots, x_{n}\right)$, one can proceed from the conditions for the investment potential indicator to determining the indicator of the process of recognizing the investment environment $\Delta t_{P I}=f_{2}\left(y_{1}, y_{2} \ldots, y_{n}\right)$ and the resulting indicator of the investment potential management $\Delta t_{P N}=f_{3}\left(z_{1}, z_{2} \ldots, z_{n}\right)$. Here vector $X$ characterizes the process of formation of the investment problem in managing the investment potential. Vector $Y$ is the recognizing of the investment environment, and $Z$ is the process of neutralizing the investment problem. In general, the paper proposes the basics of building a technology for managing the investment potential. The synthesis of the investment potential management system based on a system of differential equations allowed us to implement a guaranteed approach to investment potential management. The management model, the graph of states in particular, can be further complicated by introduction of additional feedbacks and other conditions.

\section{Funding}

The research is partially funded by the Ministry of Science and Higher Education of the Russian Federation as part of World-class Research Center program: Advanced Digital Technologies (contract No. 075-15-2020-934 dated 17.11.2020)

Ethical Approval. Not applicable.

\section{Consent to Participate:}

The authors have consent to participate.

\section{Consent to Publish:}

The authors have consent to publish.

\section{Authors Contributions:}

Study conception and design: Sergey Chernogorskiy

Acquisition of data: Konstantin Kostin

Analysis and interpretation of data: Bernd Mühlfriedel

Drafting of manuscript: Sergey Chernogorskiy

Competing Interests. There is no any conflict of interest to declare.

Availability of data and materials: The data that support the findings of this study are available from the corresponding author

\section{References}

1. Taleb, N. N. The black swan: The impact of the highly improbable. Published by Random House, 2007, 366 p. 
2. Grinin L., Korotayev A., Tausch A. Economic Cycles, Crises, and the Global Periphery. Springer International Publishing Switzerland, 2016, 265 p.

3. Mankiw, G. Macroeconomics. New York: Worth Publishers, 2016, 608 p.

4. Choi, K.-H., \& Shin, S. Population aging, economic growth, and the social transmission of human capital: An analysis with an overlapping generation's model (2015) Economic Modelling, 50, p. 138-147.

5. Yakita, A. Population Aging, Fertility and Social Security, Springer International, 2017, 237 p.

6. Dalio, R. A Template for Understanding Big Debt Crises. Westport: Bridgewater, 2018. 471 p.

7. Hirt, G., Block, S. Fundamentals of Investment Management McGraw-Hill Education; 10 edition, 2011, 688 p.

8. Duffie, D., Singleton, K.J. Modeling term structures of defaultable bonds (1999) Review of Financial Studies, 12 (4), pp. 687-720.

9. Jarrow, R.A., Turnbull, S.M. Pricing Derivatives on Financial Securities Subject to Credit Risk (1995) The Journal of Finance, 50 (1), pp. 53-85.

10. Papadopoulou, A.A. Some results on modeling biological sequences and web navigation with a semi Markov chain (2013) Communications in Statistics - Theory and Methods, 42 (16), pp. 2853-2871.

11. D'Amico, G., Janssen, J., Manca, R. A non-homogeneous semi-Markov reward model for the credit spread computation (2011) International Journal of Theoretical and Applied Finance, 14 (2), pp. 221-238.

12. Collin-Dufresne, P., Goldstein, R.S., Martin, J.S. The determinants of credit spread changes (2001) Journal of Finance, 56 (6), pp. 2177-2207.

13. Crouhy, M., Galai, D., Mark, R. A comparative analysis of current credit risk models (2000) Journal of Banking and Finance, 24 (1-2), pp. 59-117.

14. D'Amico, G. A semi-Markov maintenance model with credit rating application (2009) IMA Journal of Management Mathematics, 20 (1), pp. 51-58.

15. Sonin, I. The asymptotic behaviour of a general finite nonhomogeneous Markov chain (the decompositionseparation theorem) (1996) Stat Prob Game Theory, 30, pp. 337-346.

16. Jarrow, R.A., Yu, F. Counterparty risk and the pricing of defaultable securities (2001) Journal of Finance, 56 (5), pp. 1765-1799.

17. Altman, E.I., Rijken, H.A. How rating agencies achieve rating stability (2004) Journal of Banking and Finance, 28 (11), pp. 2679-2714.

18. Duffie, D. Measuring Corporate Default Risk (2011) Measuring Corporate Default Risk, pp. 1-128.

19. Ashby W.R. An Introduction to Cybernetics. Chapman \& Hall LTD. London, 1956. 432 p.

20. Harrison E.F, Pelletier M.A. A typology of strategic choice. Technological Forecasting and Social Change. 1993. No. 44(3). Pp. 245-263.

21. Harrison E.F. Interdisciplinary Models of Decision Making. Management Decision. 1993. No. 31(8). Pp. $27-$ 33.

22. Darvish M., Yasaei M., Saeedi A. Application of the graph theory and matrix methods to contractor ranking. International Journal of Project Management. 2009. Vol. 27. No. 6. Pp. 610-619.

23. Hatush Z., Skitmore M. Contractor Selection Using Multicriteria Utility Theory: An Additive Model. Building and Environment. 1998. Vol. 33. No. 2. Pp. 105-115.

24. Cheng E. W.L., Li H. Contractor selection using the analytic network process. Construction Management and Economics. 2004. Vol. 22. No. 10. Pp. 1021-1032.

25. Chan A.P.C., Chan A.P.L. Key performance indicators for measuring construction success. Benchmarking. 2004. Vol. 11. No. 2. Pp. 203-221.

26. Komov V.M., Korotkov A.A. Determining the probability of states of the construction production system. Vestnik grazhdanskikh inzhenerov. 2015. No. 3 (50). Pp. 140-147. (rus)

27. Golovan A.M., Klashanov F.K., Petrova S.N. To the theoretical basics of building up models of construction management. Vestnik grazhdanskikh inzhenerov. 2013. No. 5 (40). Pp. 208-212. (rus)

28. Gulenko O.I. Construction of a model of management of sustainable development of a socio-economic system. Vestnik Udmurtskogo universiteta. Seriya ekonomika i pravo. 2015. No. 6. Pp. 14-20. (rus)

29. Klashanov F.K. Creation of the logical-linguistic model of the system of construction management. Nauchnoye obrazovaniye. 2015. No. 14. Pp. 370-373. (rus)

30. Galeyeva Ye.I. Innovative technologies in the management of socio-economic systems. Problemy sovremennoy ekonomiki. 2008. No. 3. Pp. 68-73. (rus)

31. Burlov V.G. The fundamentals of modeling socioeconomic and political processes (Methodology. Methods). Saint-Petersburg, SPbGPU, 2006. 270 p. (rus) 
32. Burlov V., Chernogorskiy S., Shvetsov K. An inverse solution-based conception of guaranteed control of the RF Arctic Zone's sustainable development. In Global economic processes, Didenko N., Saint-Petersburg, SPbPU, 2016, pp. 84-95. (rus)

33. Kalinin V.N., Reznikov B.A., Varakin Ye.I. Systems theory and optimal management. Part 1. Basic concepts, mathematical models and methods of systems analysis. Saint-Petersburg, VIKI im. A.F. Mozhayskogo, 1979. 320 p. (rus)

34. Goode H.H., Machol R.E. System Engineering: An Introduction to the Design of Large-Scale Systems. McGraw-Hill Book Co. New York, 1957. 551p.

35. Arbib M.A. Brains, Machines and Mathematics. McGraw-Hill Book Co. New York, 1964. 494 p.

36. Kalman, R.E. Topics in mathematical system theory. McGraw-Hill Book Co. New York, 1974. 358 p.

37. Burlov V.G., Grobitski A.M., Grobitskaya A.M. Construction management in terms of indicator of the successfully fulfilled production task. Magazine of Civil Engineering. 2016. No. 3. Pp. 77-91. doi: 10.5862/MCE.63.5

38. S. Sabirova et al. Choosing a quality management method. 2019 IOP Conf. Ser.: Mater. Sci. Eng. 666012043 doi:10.1088/1757-899X/666/1/012043

39. Anokhin P.K. Essays on Physiology of Functional Systems. Moscow: Meditsina, 1975. 448 p. (rus)

40. Papadakis V.M., Lioukas S., Chambers D. Strategic decision-making processes: The role of management and context. Strategic Management Journal. 1998. Vol. 19. No. 2. Pp. 115-147.

41. Lu M., Li H. Resource-activity critical-path method for construction planning. Journal of Construction Engineering and Management. 2003. Vol. 129. No. 4. Pp. 412-420.

42. Simpson III W.P., Patterson J.H. A multiple-tree search procedure for the resource-constrained project scheduling problem. European Journal of Operational Research. 1996. Vol. 89. No. 3. Pp. 525-542.

(C) 2020 by the authors. Submitted for possible open access publication under the terms and conditions of the Creative Commons Attribution (CC BY) license (http://creativecommons.org/licenses/by/4.0/). 


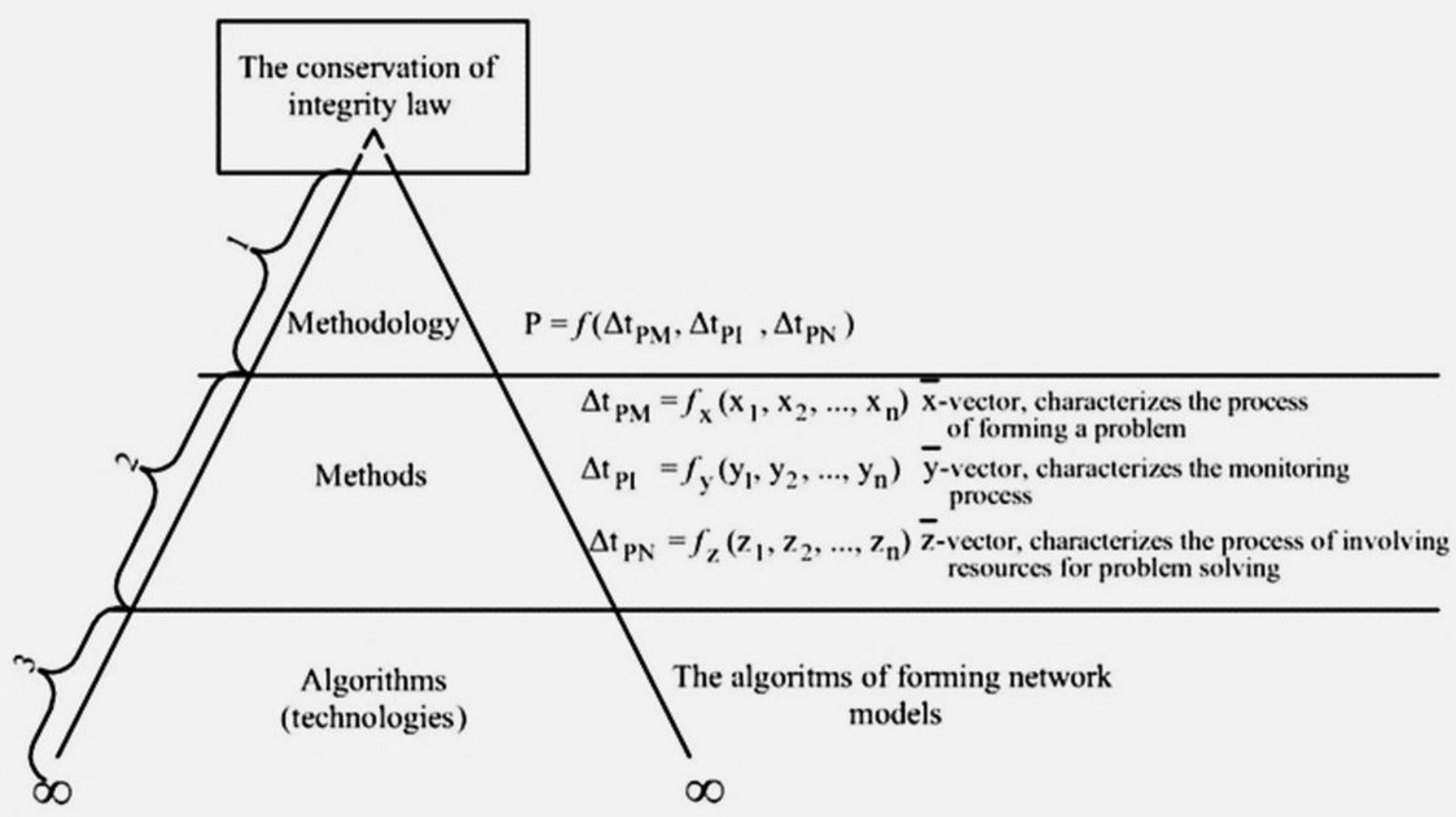

Figure 1

The structural diagram of the "Investment decision" concept [31,32]. 


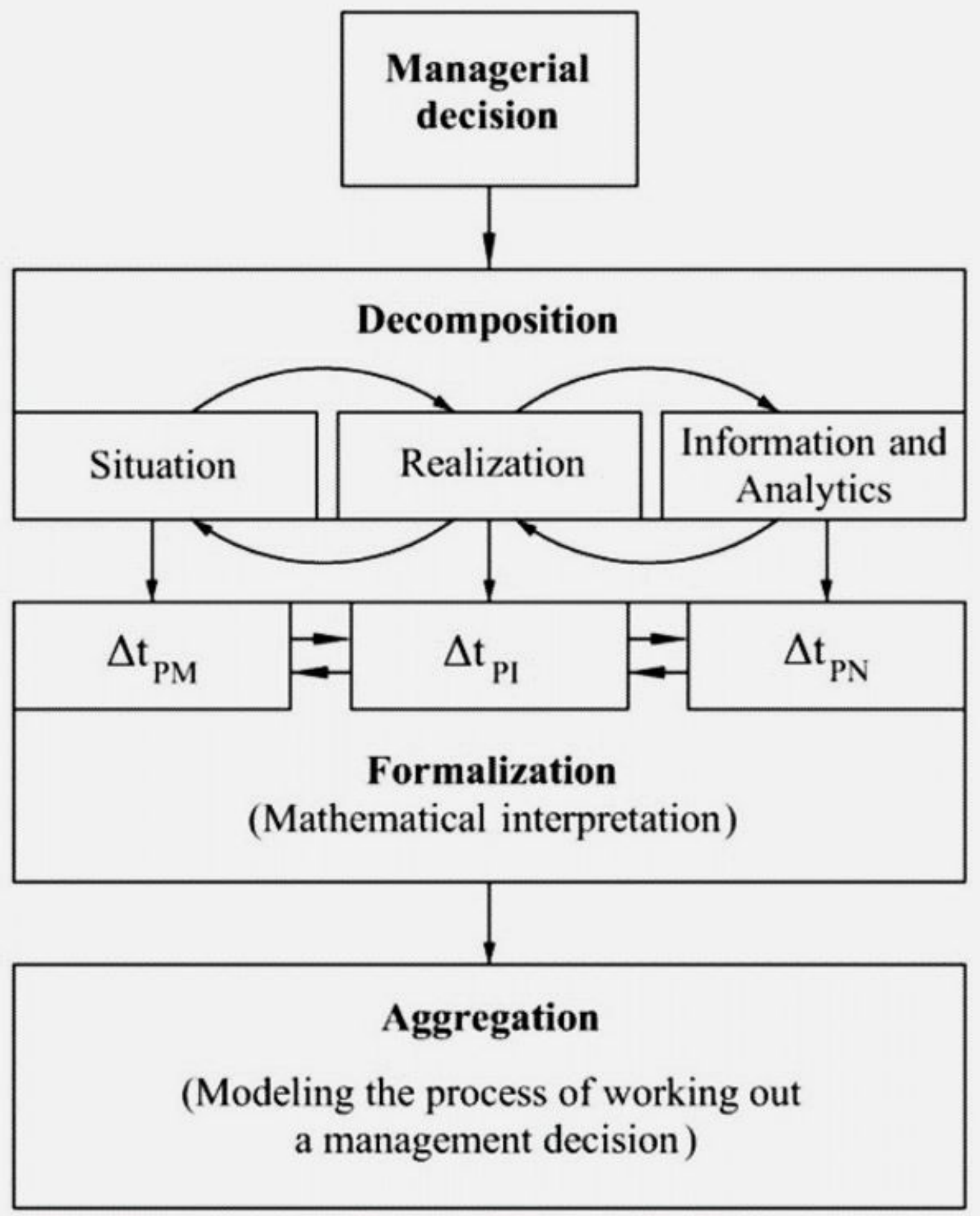

Figure 2

Structural diagram of the synthesis process of the model construction $[37,32]$. 
a)
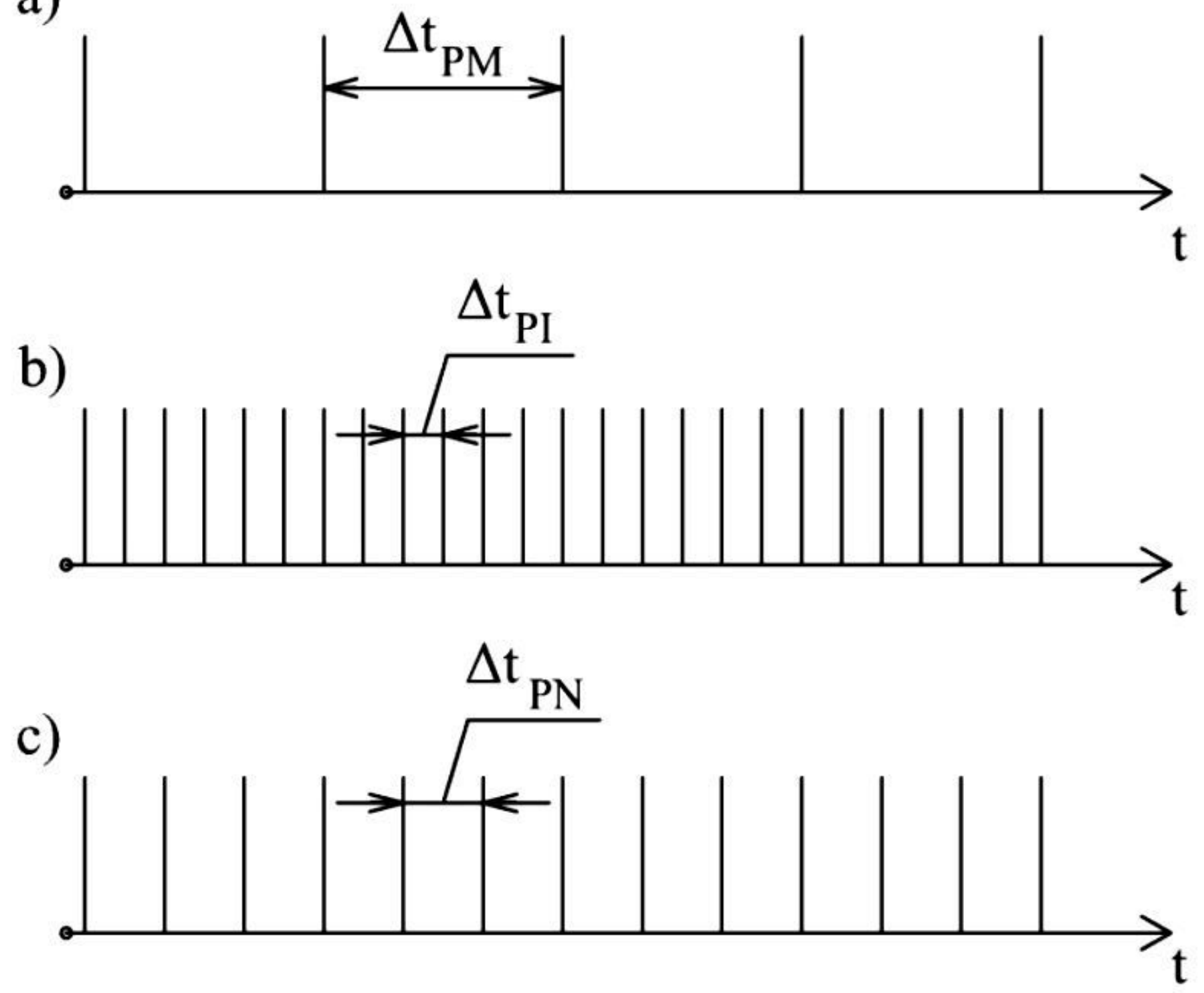

Figure 3

A diagram of the basic elements in the construction of the investment decision model $[31,37]$. 


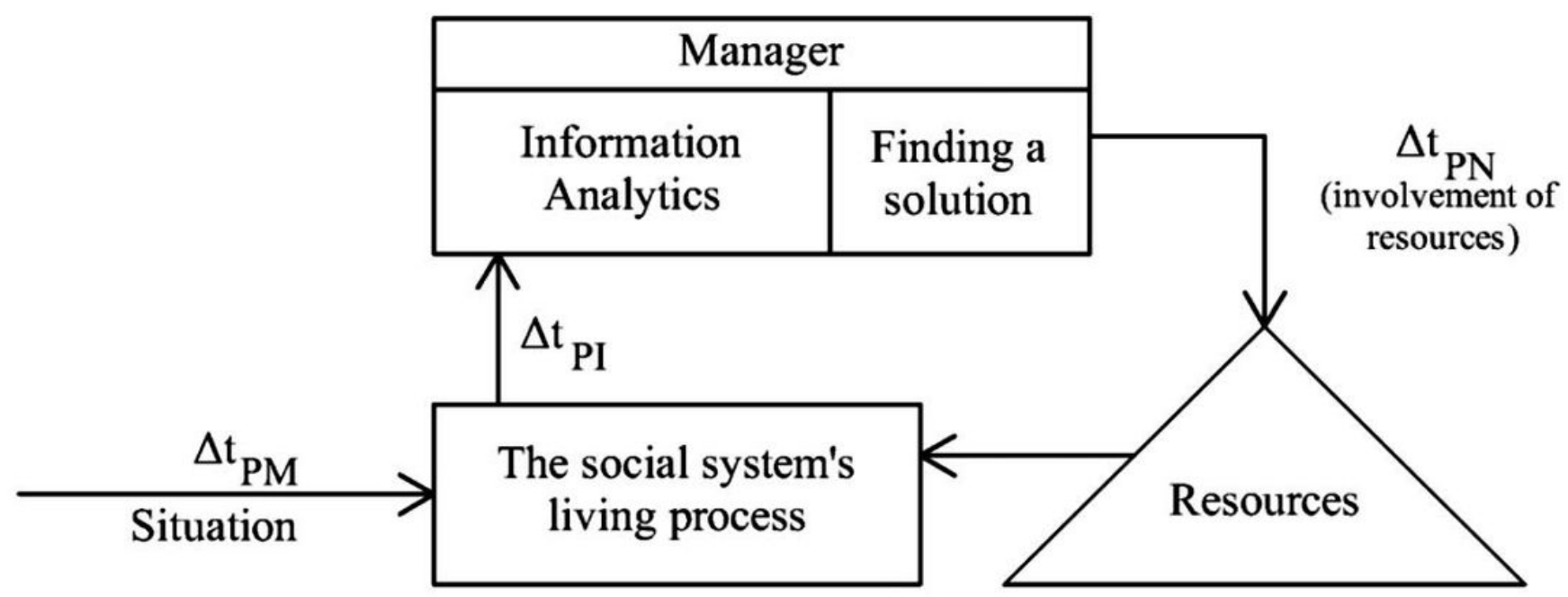

Figure 4

The block diagram of the investment process management [38], $\lambda$ is the reciprocal value of the average time the investment problem emerges; $v 1$ is the reciprocal value of the average time of identification of the investment problem; $\mathrm{v} 2$ is the reciprocal value of the average time the investment problem is neutralized.

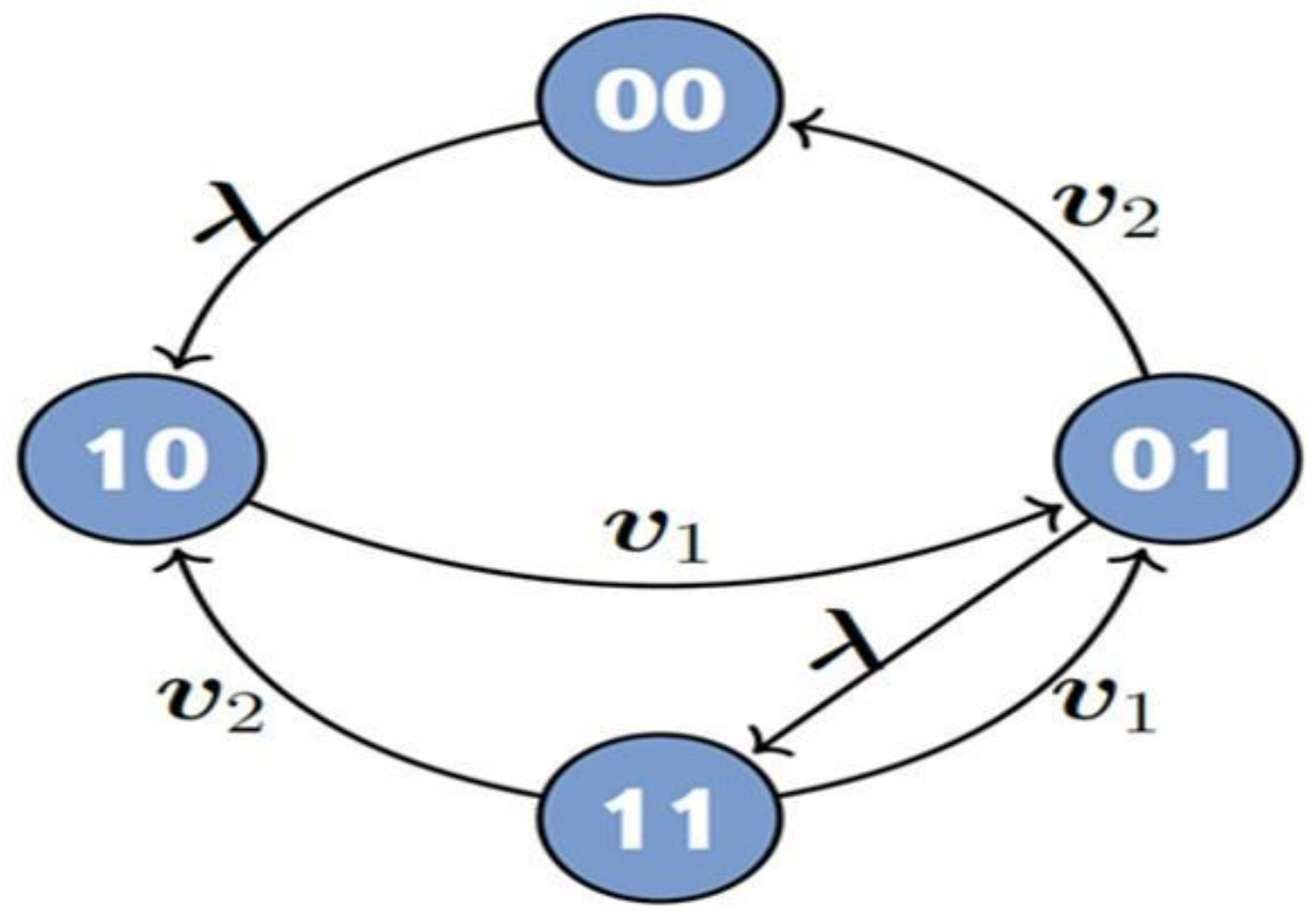

Figure 5 
The graph of states of the system [designed by authors]

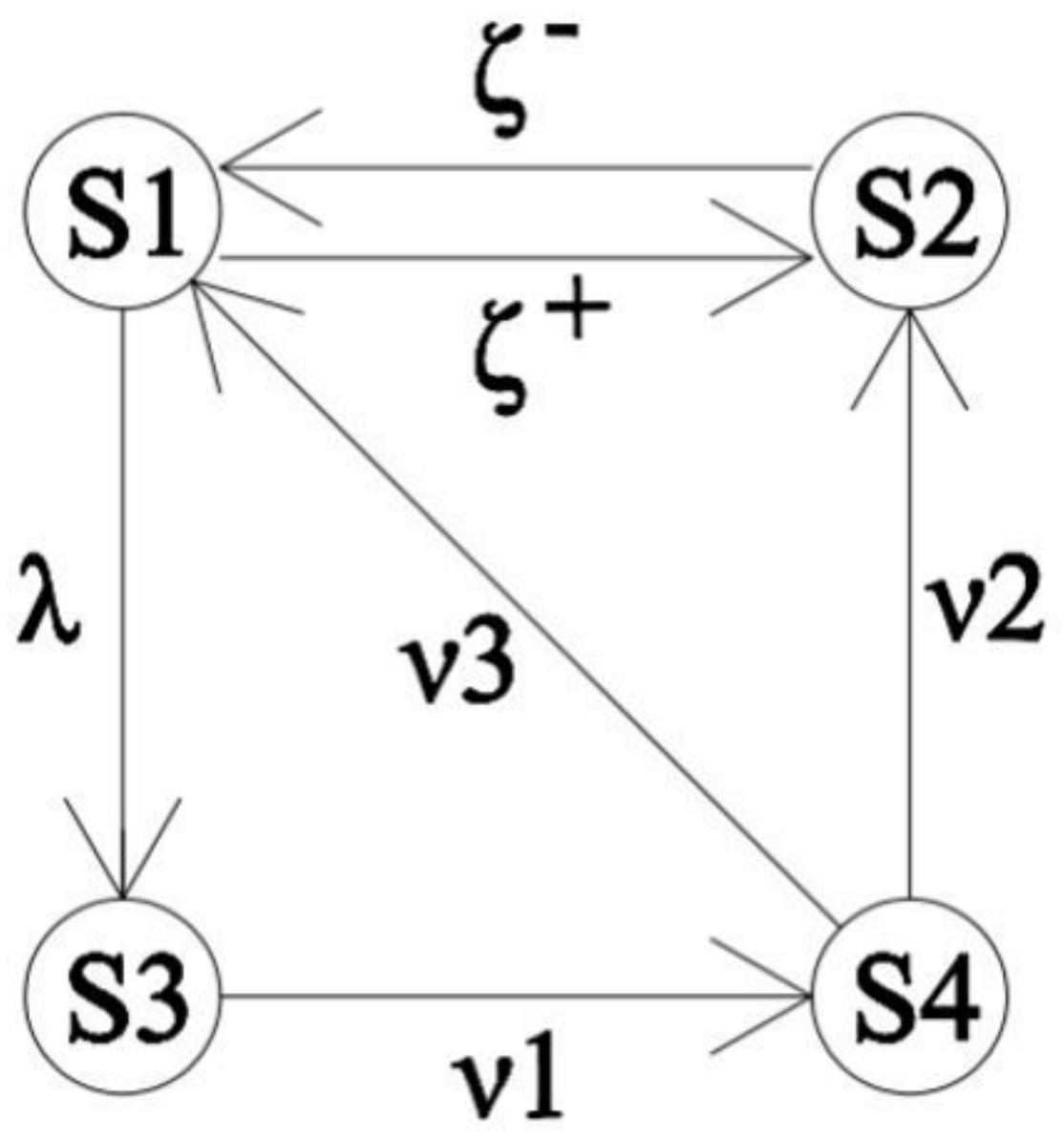

Figure 6

Graph of states of the system [designed by authors] 